\title{
Analysis of Students' Understanding for the Concept of Matrix Rank Based on APOS Theory
}

\author{
Siti Inganah \\ University of Muhammadiyah Malang \\ singanah@gmail.com
}

\begin{abstract}
This current research aimed to explore the students' level in understanding in the concept of matrix rank based on the APOS (Action, Process, Object, and Schema) theoretical framework. Qualitative approach and exploratory type were employed. The subjects in this research were the students of mathematics department which consist of 48 people. The first data was collected by giving the assignment about matrix rank to 48 students. Then based on the result of the assignment, in-depth interviews was employed to 6 students to collect more data. The results showed that the level of students' understanding in the concept of matrix rank lies at the four stages of the APOS theory framework.
\end{abstract}

Keywords: understanding, APOS theory, matrix rank

\section{INTRODUCTION}

Matrix rank is one of topics in matrix algebra course that must be taken by Mathematics Department students. Based on the researcher's experience as a lecturer of matrix algebra course, the students often have a difficulty in understanding the concept of matrix rank. The results showed that there was a significant positive correlation between the student's achievement in the matrix algebra course with linear algebra course [1].

The general dimension of the row space and column space of the matrix A is called rank $\mathrm{A}$ and is denoted by rank (A) [2]. The concept of matrix rank is defined that if $\mathrm{A}$ is not a zero matrix, then $\mathrm{A}$ is said to have rank $r$ if at least one minor square has size of $r \times r \neq 0$ and if there is a minor square $(r+1) \times$ $(r+1)=0$ [3]. The concept of matrix rank studied in this research is connected with minor and determinant concepts. The concept is a meaningful idea [4]. Understanding the previous concepts of mathematic can significantly predict the further mathematical achievement [5].

APOS is a constructivist theory developed for mathematics education and can be used to analyze the students' mental constructions in learning mathematical concepts [6]-[8]. The suitability of intervention given by the lecturers with the students' thinking process in understanding the mathematical concepts can be done through the application of APOS stages [9]. The phases of APOS theory support the process to describe the learning sequences of mathematical induction in universities and the student's strategies in constructing vector space concepts [10]-[11].

One's mathematical knowledge is a tendency to respond to situations of mathematical problems by reflecting on problems and solutions in the social context through actions, processes, objects and schemes [12]. When someone notices and realizes the action or operation, he/ she is able to continue the process, then summarizes the process to an object [13]. Actions, processes, and objects are organized in mental structures called schemes [12]. The mental mechanism for building mental structures is called interiorization and encapsulation [14].

Several studies on the application of APOS theory have been conducted. One of them reveals that the theory of APOS is a very useful framework to test the understanding of engineering students about a topic which associated with loop and nested loops [6]. The student's ability in the proof of abstract algebra increased significantly through the application of APOS [15]. The students' ability to construct eigenvalues, eigenvectors, and eigenspaces increase significantly when taught using phases of APOS theory [16]. The APOS theory is able to improve the students' mental constructions in solving problems about trigonometric functions [17]. This study is different from previous research that has been done. This study aims to explore the students' understanding about the concept of a matrix based on the framework of APOS theory.

\section{METHOD}

This research uses qualitative approach and explorative type, because it describes the students' understanding about the concept of matrix rank based on the naturally occurring circumstances. The research subjects were the students who take matrix algebra course. The data collection was done through giving the assignment about matrix rank to the 48 students. Then based on the result of the assignment, the data was categorized into three categories of understanding, which are high, medium, and low. 


\section{RESULT}

In this study, it reveals that the understanding of matrix rank concept is indicated by the following indicators: 1) restating the concept of matrix rank, 2) implementing the concepts of matrix rank, either on the square matrix or non-square matrix, 3) choosing a particular procedure or operation to determine the matrix rank, and 4) developing necessary terms or sufficient terms of matrix rank concept. The ability of the subjects in understanding the concept of matrix rank in this study was studied based on the APOS theory framework.

\section{Stage Action}

At the stage of action, the subject in high category is able to comprehend the concept of the rank matrix which is simplify the matrix form by performing some elementary row operations to obtain the matrix with the elements of all zeros in the last row. Figure 1 shows the understanding of the high-ability subjects at the stage of action.

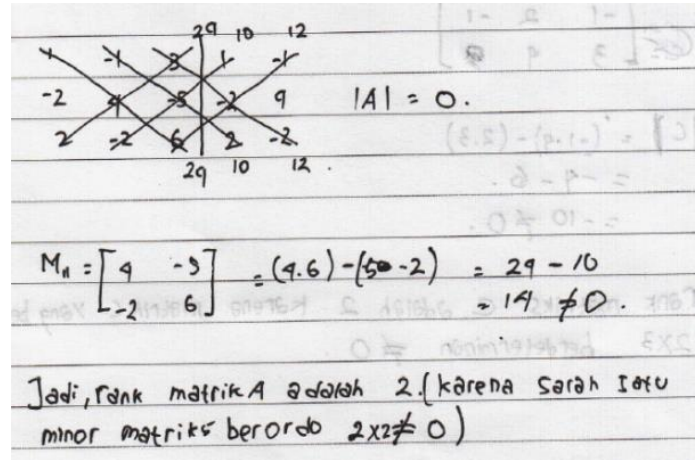

Figure 1. The work of SS2 at the action stage

Based on the simple matrix that had been obtained as in Figure 1, the subject is able to determine that the determinant of the obtained $3 \times 3$ matrix is zero. Next, the subject is able to determine one of the non-zero $2 \times 2$ minor, so it is concluded that the matrix rank is two. The high-ability subject's understanding of the concept in action stage is similar with the medium-ability subject.

The low-ability subjects, in the stage of action, the subject is able to determine the rank matrix $A_{3 \times 3}$ by finding the determinant using the rules of Sarrus. This is apparent in the work of SR1 in Figure 2.

The work of SR1 in Figure 2 shows that, the subject is able to determine the rank of matrix A correctly. The subject states that the rank matrix $\mathrm{A}$ is 2 by a reason that one of the $2 \times 2$ minor sectors of the matrix A is 14 , which is not equal to zero.

\section{Process Stage}

At the process stage, the high-ability subjects are able to explain the reason for obtaining the rank matrix $A_{3 \times 3}$ that worth 2 . The high-category subjects are able to develop the necessary or sufficient condition of the matrix rank concept.

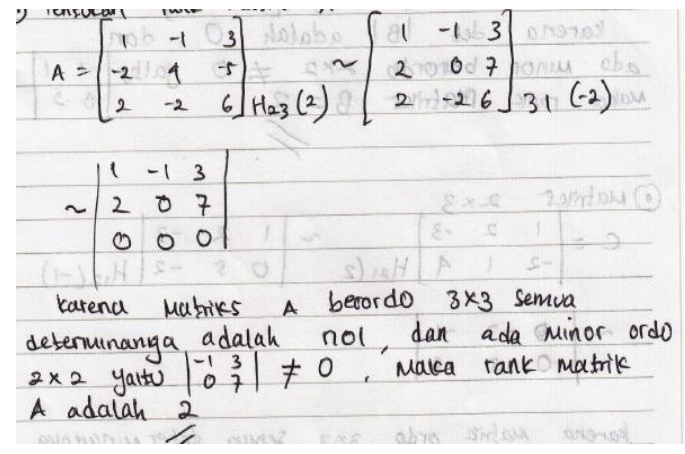

Figure 2. The work of SR1 at the action stage

The medium-ability subjects are also able to explain the reason for the calculation of the $3 \times 3$ matrix rank. The subjects are able to explain the principle or the requirement of rank matrix applicable to the $3 \times 3$ matrix. The subjects of low-ability are also able to explain the reason for obtaining rank of matrix $A_{3 \times 3}$.

Object Stage

At the object stage, the high-ability subjects are able to transform the concept of $\mathrm{m} \times \mathrm{n}$ matrix rank. The strategy in determining the matrix rank that was used is fixed, by performing elementary row operations to obtain a simple matrix, as shown in the work of ST1 in the Figure 3.

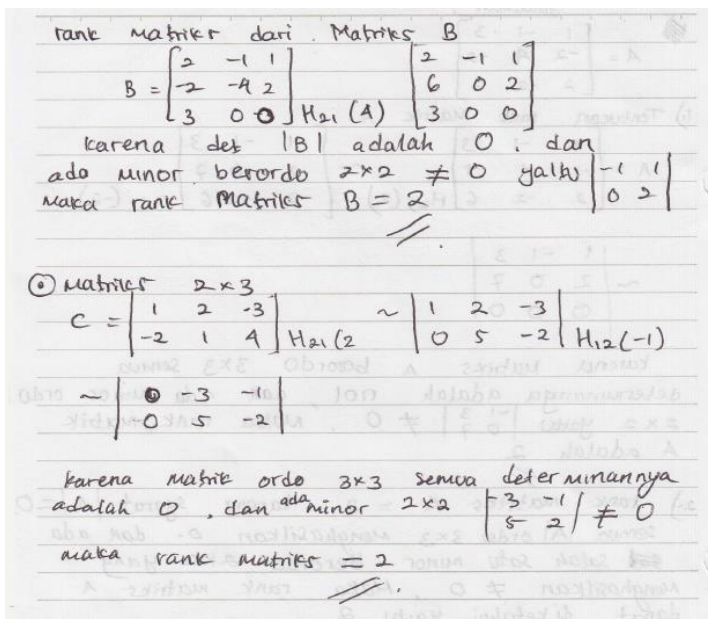

Figure 3. The work of ST1 at the object stage

Based on the Figure 3, it shows that the highability subjects are able to transform the concepts and principles of matrix rank by giving examples to other matrix.

The medium-ability subjects are also capable to transform the concepts and principles of matrix rank. This is indicated by the quotation of the work of a medium-ability subject (SS2) as shown in the Figure 4. 


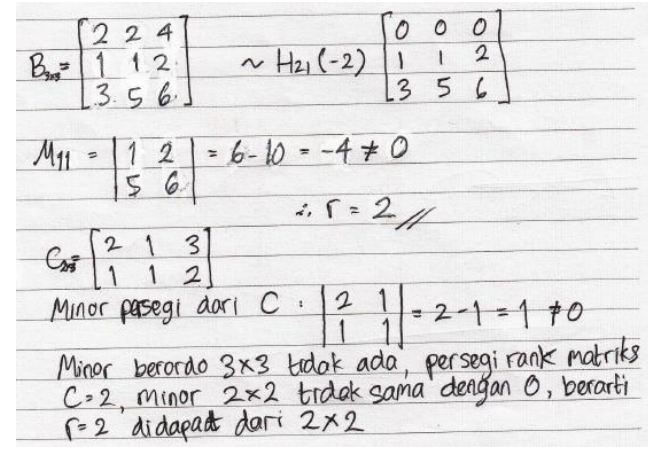

Figure 4. The work of SS2 at the Object stage

The Figure 4 shows that the example given to the medium-ability subjects to determine the $2 \times 3$ matrix rank that also has several elements of the same number, making it easy to define a minor $2 \times 2$. The low-ability subjects are also capable to transform the concept of rank matrix, but it is incomplete.

\section{Scheme Stage}

At the scheme stage, the high-ability subjects are able to organize the stage of action, process, and object to explain the concept of the matrix rank. This is seen in the following excerpt of the ST1's work in the Figure 5.

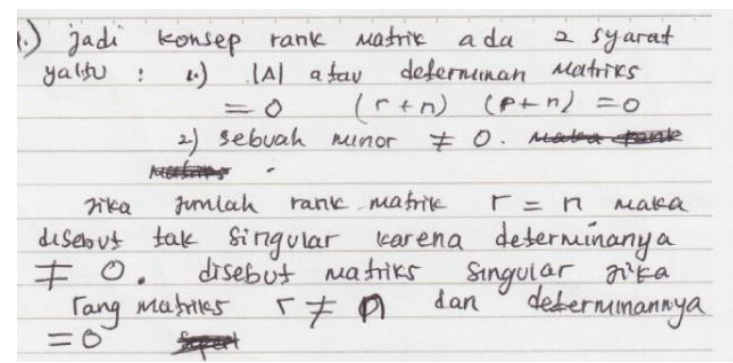

Figure 5. The work of ST1 at the Scheme stage

According to Figure5, it appears that the subject explains, if the matrix $\operatorname{rank} A_{n \times n}$ is $r \neq n$ and the determinant is equal to zero. Subjects are able to reiterate the concepts and principles of matrix rank that are associated with the concept of singular and non-singular matrices.

Meanwhile, the medium-ability subjects are not able to re-explain the concept of matrix rank. The low-ability subjects are also unable to re-explain the concept and principle of matrix rank.

\section{DISCUSSION}

The results of this researh indicate that at the action stage, the high-ability subjects are able to realize the concept of matrix rank. The subject simplifies the matrix by performing some elementary row operations. The results of this study fit with the finding [4], that states the students use Gaussian elimination or elementary row operations to determine the matrix rank.

The high-ability subjects' understanding of the concept at the action stage is in line with the medium-ability subjects. The low-ability subjects at the stage of action are also able to determine the
$A_{3 \times 3}$ rank matrix, but in determining the determinant was done using the Sarrus rules. This point supports the research finding [6] which state that APOS theory is an useful framework to test the students' understanding.

At the process stage, the high-ability subjects are able to explain the technique to solve the $A_{3 \times 3}$ matrix rank. The high-ability subjects are able to develop the necessary or sufficient condition of the matrix rank concept. The medium and low-ability subjects are also able to explain the technique to solve the $3 \times 3$ matrix rank.

At the object stage, the high-ability subjects are able to transform the concept of the $3 \times 3$ matrix rank. The medium-ability subjects are also capable of transforming the concepts and principles of rank matrices by providing some examples of how to determine the matrix rank. The low-ability subjects are also capable of transforming the concept of matrix rank, but it is incomplete.

At the scheme stage, the high-ability subjects are able to organize the stages of action, process, and object to explain the concept of matrix rank. The subjects are able to reiterate the concepts and principles of matrix rank that are associated with the concept of singular and non-singular matrices. The results of this research support one of the finding [5] which shows the decomposition of the numerical value of numerical matrices. Meanwhile, medium and low-ability subjects are not able to re-explain the concept and principle of matrix rank. The results of this research are in accordance with the findings [7], which indicate that the difficulty or failure to understand mathematics concepts can be solved by using the APOS framework.

\section{CONCLUSION}

The results of this research reveal that at the action stage, the students, either high, medium, or low-ability are able to determine the matrix rank correctly. The students in high and medium-ability are able to perform process stages, by explaining how to determine the matrix rank as well as associate it with concepts and principles. Meanwhile, the lowability students are unable to explain how to determine the matrix rank and its relation to the concepts and principles that have been studied. At the object phase, the high-ability students are able to transform the concept of matrix rank to determine the matrix rank by giving another example. However, the medium and low-ability students encounter some errors. At the scheme stage, the high-ability students are able to organize action, process, and object stage to re-explain the concept of matrix rank correctly. However, the medium and low-ability students are unable to re-explain the concept of matrix rank matrices. 


\section{REFERENCES}

[1] Suryaningsih, Y. "Korelasi Hasil Belajar Matakuliah Aljabar Elementer Mahasiswa Program Studi Pendidikan Matematika FKIP Universitas Lambung Mangkurat Berdasarkan Matakuliah Prasyarat." EDU-MAT Jurnal Pendidikan Matematika, Vol: 4, hal. 118 - 125. 2016.

[2] Anton, H., Rorres, C., Aljabar Linier Elementer Versi Aplikasi.” Erlangga: Jakarta. 2004

[3] Ayres, Frank. Teori dan Soal-Soal Matriks.Jakarta: Erlangga.1994.

[4] Dubinsky, E., Weller, K., Stringer, C. \& Vidakovic, D. "Infinite iterative process:the tennis ball problem. European Journal of Pure and Applied Mathematics, Vol:1, Page: 99-121. 2008.

[5] Ching-Yi Lee, Hsin-Yi Kung. "Math SelfConcept and Mathematics Achievement: Examining Gender Variation and Reciprocal Relations among Junior High School Students in Taiwan, " EURASIA Journal of Mathematics, Science and Technology Education, Vol: 14, page: 1239-1252, 2018-0526

[6] Cetin,Ibrahim, “Students'Understanding of Loops and Nested Loops in Computer Programming: An APOS Theory Perspective,"Canadian Journal of Science, Mathematics and Technology Education, Vol: 15, Page: 155-170, 2015.

[7] Dubinsky, Ed. \& Mcdonald, Michael A., "APOS : A Constructivist Theory of Learning in Undergraduate Mathematics Education Research," The Teaching and Learning of Mathematics at University Level, 2002

[8] Tziritas, Mathew, "APOS Theory as a Framework to Study the Conceptual Stages of Related Rates Problems, Analysis, Vol: 43, Page: 213-218, 2011

[9] Inglis, Matthew, "Review of APOS Theory: A Framework for Research and Curriculum Development in Mathematics Education," International Journal of Research in Undergraduate Mathematics Education, Vol: 1, Page: 413-417, 201

[10] García-Martínez, IsabelParraguez, \& Marcela, "The basis step in the construction of the principle of mathematical induction based on APOS theory," Vol: 46, Page: 128-143, 2017

[11] Parraguez, Marcela \& Oktaç, Asuman, “ Construction of the vector space concept from the viewpoint of APOS theory," Linear Algebra and Its Applications, Vol: 432, Page: 21122124, 2010.

[12] Asiala, M., Cottrill, J., Dubinsky, E. \& Schingendorf, K.E. "The Development ofStudents' Graphical Understanding of the Derivative," Journal of MathematicalBehavior, 16(4), 1997.

[13] Haryanto dan Suyono. Belajar dan Pembelajaran. Bandung: PT Remaja Rasdakarya. 2009

[14] Dubinsky, Ed \& Moses, R.P. "Philosophy, Math Research,Math Ed Research, K-16 Education, and the CivilRights Movement:A Synthesis." Notices of The AMS.Vol. 58. No. 3. 401-409. 2011

[15] Arnawa, I., Kartasasmita, B. \& Baskoro, ET., "Applying The APOS Theory to improve students ability to prove in elementary abstract algebra," Journal of the Indonesian Mathematical Society, Vol: 13, Page: 133-148, 2007

[16] Salgado, Hilda \& Trigueros, María, “ Teaching eigenvalues and eigenvectors using models and APOS Theory," Journal of Mathematical Behavior, Vol: 39, Page: 100120, 2015

[17] Martínez-Planell, Rafael, Cruz \&Delgado, Angel, " The unit circle approach to the construction of the sine and cosine functions and their inverses: An application of APOS theory, Journal of Mathematical Behavior, Vol: 43, Page: 111-133, 2016. 